\section{Ranah Sasaran dalam Metafora Kata /Yadun/'Tangan' pada Alquran}

\author{
Regi Fajar Subhan \\ Department of Linguistics \\ Universitas Padjadjaran \\ regifsubhan28@gmail.com
}

\begin{abstract}
ABSTRAK
Makalah ini mendeskripsikan konsep-konsep ranah sasaran yang terdapat dalam ayat-ayat metaforis berunsur anggota tubuh khususnya tangan. Metafora sering digunakan dalam upaya berbahasa yang dapat ditemukan dalam setiap bahasa di dunia, tak terkecuali dalam teks-teks keagamaan yang salah satunya ialah kitab suci Alquran. Metafora didefinisikan sebagai bentuk pemahaman satu ranah konsep melalui ranah konsep lain, atau dengan kata lain upaya pengongkretan konsep abstrak dalam berbahasa. Ranah sasaran merupakan wilayah yang abstrak dan menjadi sesuatu yang dituju dari metafora. Kitab Alquran merupakan kitab suci penganut agama Islam di seluruh dunia. Isi pesannya selain dinyatakan secara eksplisit juga ada yang dinyatakan secara implisit dengan menggunakan bentuk-bentuk kiasan. Salah satu bentuk tersebut dinyatakan melalui metafora dengan unsur anggota tubuh. Benda-benda yang melekat ditubuh menjadi sesuatu hal yang dekat dengan konsep pemikiran dan kognisi manusia. Dalam hal ini, "tangan" sebagai salah satu anggota tubuh memiliki peran dalam melakukan berbagai tindakan. Metodologi penelitian yang digunakan yakni kualitatif deskriptif, meliputi tiga tahap metode, di antaranya: peyediaan data, penganalisisan data, dan penyajian data. Teori metafora yang digunakan mengacu pada Lakof dan Johnson (1980; 2003), Kövecses (2010), dan Saeed (2016). Sumber utama data berasal dari kitab Alquran, sedangkan sumber pendukung ialah buku tafsir yang digunakan sebagai uji validitas. Hasil penelitian menyatakan bahwa ranah sasaran metafora berunsur kata /yadun/ 'tangan' dalam Alquran terdiri dari: (1) ranah sasaran sifat, (2) ranah sasaran pemalsuan, (3) ranah sasaran pertanggungjawaban, (4) ranah sasaran kekuasaan, (5) ranah sasaran menahan emosi, (6) ranah sasaran meluapkan emosi (mencelakai), dan (7) ranah sasaran kerugian.
\end{abstract}

Kata kunci: metafora; ranah sasaran'; tangan; Alquran

\title{
PENDAHULUAN
}

Pembahasan mengenai bahasa tak hanya terkait dengan struktur morfologi dan sintaksis semata. Lebih jauh lagi, pembahasan mengenai makna menjadi suatu tujuan utama dalam upaya pembelajaran bahasa yang sedang dipelajari. Dalam linguistik kajian yang membahas makna ialah semantik (dalam linguistik Arab dinamakan Silmu 'd-dilālah). Berdasarkan perkembangannya, pandangan baru dalam ilmu linguistik muncul sekitar tahun 1980 yang dikenal dengan linguistik kognitif. Kajian ini merupakan bentuk pandangan atau paham baru dari linguistik yang dipadukan dengan pengalaman kognitif. Salah satu pembahasannya ialah semantik kognitif yang di dalamnya menjelaskan tentang metafora konseptual.

Pandangan ini diperkenalkan oleh Lakoff dan Johnson (1980). Teori yang diberikan oleh keduanya kemudian sangat berpengaruh hingga memunculkan banyak linguis lain penganut kognitif seperti Langacker (1987), Turner (1987), Taylor (1995), Fauconnier (1997), Talmy (2000), Kövecses (2002), dan lain-lain. Kajian kognitif sendiri baru diajarkan melalui mata kuliah dan berkembang di Indonesia memasuki tahun 2000-an (Arimi, 2015:36). Salah satu fokus pandangan ini adalah penggunaan ungkapan metafora (Evans dan Green, 2006:286). Bagi sebagian kalangan, metafora merupakan sarana puitisasi dan penghias retorika melalui penggunaan bahasa yang tidak biasa. Sesuai judul di atas, berikut penulis berikan contoh metafora dalam ayat Alquran.

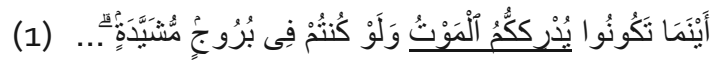

$\begin{array}{llll}\text { Paynamā } & \text { takūnū } & \text { yudrikkumu } & \text { 'l-mawtu } \\ \text { di mana saja } & \text { kalian berada } & \text { akan mendapatkan kalian } & \text { kematian }\end{array}$


Ranah Sasaran dalam Metafora Kata /Yadun/'Tangan' pada Alquran

\begin{tabular}{|c|c|c|c|}
\hline $\begin{array}{l}\text { walaw } \\
\text { kendatipun }\end{array}$ & $\begin{array}{l}\text { kuntum fī } \\
\text { kalian di dalam }\end{array}$ & $\begin{array}{l}\text { burūji } \\
\text { benteng }\end{array}$ & $\begin{array}{l}\text { 'm-mušayyadatin/ } \\
\text { kokoh }\end{array}$ \\
\hline $\begin{array}{l}\text { 'Di manapur } \\
\text { dalam bente }\end{array}$ & $\begin{array}{l}\text { alian berada, } \\
\text { yang tinggi } d\end{array}$ & $\begin{array}{l}\text { latian ak } \\
\text { kokoh.' (C }\end{array}$ & $\begin{array}{l}\text { mendapatkanmu, kendatipun berada di } \\
4: 78)\end{array}$ \\
\hline
\end{tabular}

Pada contoh (1), "kematian" diibaratkan memiliki sifat layaknya manusia melalui verba transitif "mendapatkan". Makna dari ayat ini ialah menjelaskan bahwa setiap manusia suatu saat pasti akan mengalami kematian yang telah ditentukan waktu dan tempatnya. Kata "kematian" adalah bentuk nomina abstrak yang diumpamakan dapat melakukan tindakan layaknya manusia. Agar lebih jelasnya, berikut contoh ayat metafora konseptual yang menyebutkan kata يَ/yadun/ 'tangan' dalam Alquran.

(2)

\begin{tabular}{|c|c|c|}
\hline $\begin{array}{l}\text { /yadāhu } \\
\text { Kedua tangan-Nya }\end{array}$ & $\begin{array}{l}\text { mabsūțatāni } \\
\text { terbuka keduanya }\end{array}$ & $\begin{array}{l}\text { yunfiqu } \\
\text { Dia menafkahkan }\end{array}$ \\
\hline $\begin{array}{l}\text { kayfa } \\
\text { sebagaimana }\end{array}$ & $\begin{array}{l}\text { yašā } / \\
\text { Dia kehendaki }\end{array}$ & \\
\hline
\end{tabular}

'kedua tangan-Nya terbuka; Dia memberi rezeki sebagaimana Dia kehendaki.' $(\mathrm{QS}, 5: 64)$

Bentuk metafora pada contoh (2) memiliki konsep abstrak yang digunakan untuk mengongkretkan sifat. Keadaan tangan yang terbuka menunjukkan posisi tangan saat memberikan sesuatu kepada orang lain. Konsep tersebut telah penulis validasi melalui pandangan-pandangan ahli tafsir. Salah satunya dalam tafsir Jalalain yang menyebut bahwa penggalan ayat tersebut merupakan gambaran tentang sifat Allah Swt. Dengan kata lain, segala bentuk kedermawanan dilakukan dengan kedua tangan (al-Mahalli dan as-Suyuți, 2018:458). Berdasarkan kedua contoh di atas, penulis ingin menegaskan bahwa bentuk metafora konseptual pun dapat ditemukan dalam Alquran. Anggota tubuh merupakan salah satu nomina yang ditemukan di dalam Alquran untuk mengongkretkan dan mengonsepkan sesuatu yang sifatnya abstrak. Makalah ini hanya akan membahas secara mendalam anggota tubuh يَ/yadun/'tangan' saja.

Penelitian terdahulu yang sama membahas linguistik kognitif di antaranya: Golzadeh dan Pourebrahim (2013) yakni meneliti tentang metafora "kematian" dalam teks bidang keagamaan. Hasilnya menyimpulkan bahwa kematian direalisasikan sebagai PERSON, ENTITY THING, dan STAGE OF LIFE JOURNEY. Sementara Lyra (2016) meneliti tentang metafora berunsur bagian tubuh "hati" dalam bahasa Sunda, dan Chairani (2017) yang juga meneliti tentang penggunaan anggota tubuh dalam peribahasa Indonesia. Keduanya menyebut bahwa angota tubuh adalah benda-benda yang terdekat dengan pengalaman dan kognisi manusia.

Berdasarkan latar belakang yang telah dipaparkan, permasalahan yang akan dibahas selanjutnya dalam makalah ini yakni ranah sasaran apa saja yang terdapat pada metafora berunsur kata يَ /yadun/ 'tangan' dalam Alquran. Dengan demikian, penulisan makalah ini bertujuan untuk mendeskripsikan ranah sasaran yang terdapat pada metafora berunsur kata يَ /yadun/ 'tangan' dalam Alquran. Penelitian ini diharapkan menjadi pelengkap khazanah penelitian terdahulu terkait pembahasan metafora konseptual kajian semantik kognitif dalam bahasa Arab.

Kajian kognitif memandang bahwa metafora bukan hanya sekadar pemanis retoris, permasalahan linguistik, dan aspek pinggiran dari pikiran dan bahasa (Lakoff \& Johnson, 2003). Metafora merupakan pemetaan konseptual antar dua ranah yang berbeda (Kövecses, 2010), yakni aspek pengetahuan dari ranah sumber yang umumnya lebih konkret, kemudian dipetakan untuk membentuk struktur pengetahuan ranah sasaran yang cenderung lebih abstrak. Metafora mengakar pada beragam pengalaman badaniah biologis manusia dan budaya. Misalnya saja ketika acuan berbasis pada postur tegak tubuh, akan muncul skema gambaran ATAS-BAWAH (Lakoff, 1987). Skema ini yang berfungsi sebagai ranah sumber yang mendasari beragam perluasan makna metaforis dengan memetakannya ke berbagai ranah pengalaman seperti LEBIH ADALAH ATAS (pada metafora price is rising up), BAIK ADALAH ATAS (pada metafora high quality) (Lakoff \& Johnson, 2003). 
Menurut Kövecses (2010:4), "target domain is the domain that we try to understand through the use of the source domain." 'Ranah sasaran merupakan ranah yang kita coba pahami melalui penggunaan ranah sumber'. Sedangkan Saeed (2016:370) menyebutkan ranah sasaran sebagai, "the starting point or described concept", 'poin awal atau konsep yang dijelaskan'. Contoh:

\section{(3) WAKTU ADALAH UANG}

Pada contoh (3), yang memiliki kedudukan sebagai ranah sasaran ialah WAKTU, sedangkan UANG berkedudukan sebagai ranah sumbernya.

Penelitian ini menggunakan metode kualitatif dengan pemaparan secara deskriptif (Djajasudarma, 2010). Uraian metodologi yang digunakan yakni melalui pengamatan, penganalisisan, dan pendeskripsian. Sumber data penelitian diambil dari kitab Alquran. Penulis juga menggunakan teknik triangulasi, yakni menjadikan buku-buku tafsir sebagai validitas hasil agar tidak terjadi kesalahpersepsian. Teknik ini dilakukan untuk memeriksa keabsahan data dengan memanfaatkan sesuatu yang lain di luar data sebagai pembanding terhadap data itu sendiri (Moleong, 2011). Setelah dianalisis, langkah penyajian dilakukan dengan informal (Sudaryanto, 2015), yakni data hasil analisis disajikan dengan eksplanasi menggunakan kata-kata biasa secara deskriptif-objektif.

\section{ANALISIS DAN PEMBAHASAN}

Dalam bahasa Arab, kata يَد /yadun/ 'tangan' termasuk nomina (isim) feminin. Data metafora menunjukkan bahwa nomina tersebut terdiri dari beberapa redaksi dalam ayat Alquran. Redaksi yang pertama berupa bentuk infleksi jumlah yang terdiri dari bentuk tunggal/satu (mufrad), dual/dua (mutsanna), dan plural/lebih dari dua (jamak). Analisis data mencakup ketiganya. Berikut ini redaksi bentuk infleksi jumlah pada kata بَ /yadun/ 'tangan' yang dijadikan data:

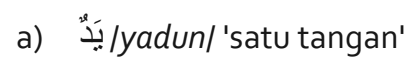

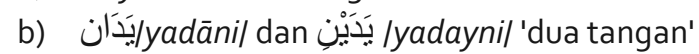

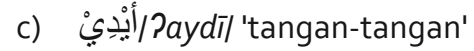

Redaksi kedua, adanya afiksasi pronomina persona dan partikel dalam tiap bentuk infleksi jumlah

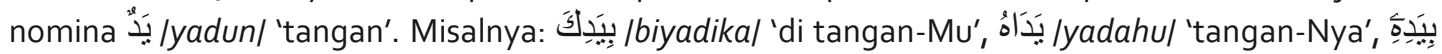

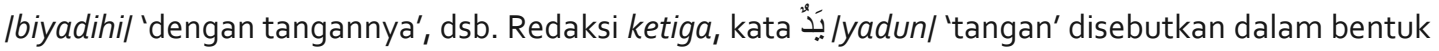

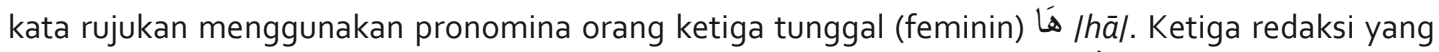
telah disebutkan merupakan temuan data sebagai unsur metafora nomina يَ /yadun/ 'tangan' yang bersanding dengan kata lainnya sehingga bermakna metaforis.

Berdasarkan hasil pencarian data analisis, ranah sasaran yang ditemukan terdiri dari: (1) ranah sasaran sifat, (2) ranah sasaran pemalsuan, (3) ranah sasaran pertanggungjawaban, (4) ranah sasaran kekuasaan, (5) ranah sasaran menahan emosi (menghentikan tindakan mencelakai), (6) ranah sasaran meluapkan emosi (mencelakai), dan (7) ranah sasaran kerugian. Untuk pemetaan kedua ranah, penulis menyajikannya dengan tabel agar memudahkan pemahaman pembaca. Berikut ini pembahasannya.

\section{Ranah Sasaran Sifat}

Ranah sasaran sifat yang dimaksud dalam pembahasan ini dimaknai sebagai keadaan yang menjadi dasar/watak/sifat yang menurut kodratnya ada pada diri manusia dan secara mutlak dimiliki Tuhan. Terdapat empat sifat tersirat dalam Alquran yang disebutkan melalui ayat metaforis berunsur lyadun/ 'tangan'. Keempat sifat tersebut terdiri dari sifat kikir, sifat pemurah, sifat berlebihan, dan sifat benci. Dalam pembahasan ini, hanya akan dibahas sifat kikir dan sifat pemurah saja. Berikut ini data yang ditemukan.

\begin{tabular}{|c|c|c|}
\hline \multirow[t]{5}{*}{1.} & \multicolumn{2}{|l|}{ يَقِبِضُوْنَ اَيْدِيَهُمْ } \\
\hline & lyaqbiọūna & Paydiyahum/ \\
\hline & mereka & tangan-tangannya \\
\hline & \multicolumn{2}{|l|}{ menggenggam } \\
\hline & \multicolumn{2}{|c|}{ 'Mereka menggenggam tangan-tangannya'. (OS, 9:67) } \\
\hline
\end{tabular}


2.

$\begin{array}{ll} & \\ \begin{array}{ll}\text { lyadāhu } & \text { mabsūțatānil } \\ \text { kedua tangan-Nya } & \text { terbuka keduanya } \\ \text { 'Kedua tangan (Allah) terbuka'. (OS, 5:64) }\end{array}\end{array}$

Berikut ini korespondensi kedua ranah serta makna metaforisnya.

Tabel 1. Korespondensi Ranah Sumber dan Ranah Sasaran /yaqbiḍūna Paydiyahum/

\begin{tabular}{|c|c|c|}
\hline Data Metafora & Ranah Sumber & Ranah Sasaran \\
\hline يَقِبِضْوُنَنَ اَيْدِيَهُهْ & 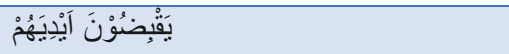 & بَخِيْلِ \\
\hline $\begin{array}{l}\text { /yaqbiọūna } \\
\text { mereka menggenggamkan }\end{array}$ & $\begin{array}{l}\text { /yaqbiọūna } \\
\text { mereka menggenggamkan }\end{array}$ & $\begin{array}{l}\text { |baxīlun| } \\
\text { kikir }\end{array}$ \\
\hline $\begin{array}{l}\text { Paydiyahum/ } \\
\text { tangan-tangannya }\end{array}$ & $\begin{array}{l}\text { Paydiyahum/ } \\
\text { tangan-tangannya }\end{array}$ & \\
\hline $\begin{array}{l}\text { 'mereka } \\
\text { menggenggamkan } \\
\text { tangannya'. (QS, 9:67) }\end{array}$ & $\begin{array}{l}\text { Pemetaan: } \\
\text { Keadaan tangan yang sedang } \\
\text { memegang entitas dengan posisi } \\
\text { jari-jari mengepal, sehingga } \\
\text { tangan terlihat menutup secara } \\
\text { kasat mata. } \\
\text { Pada saat menggenggam, pemilik } \\
\text { tangan tidak dapat memberikan } \\
\text { bantuan dan pertolongan apapun. } \\
\text { Kegiatan yang berkaitan dengan } \\
\text { aktivitas tangan tidak dapat } \\
\text { dilakukan. }\end{array}$ & $\begin{array}{l}\text { Pemetaan: } \\
\text { Keadaan seseorang yang tidak } \\
\text { ingin memberikan sebagian } \\
\text { rezekinya kepada orang lain. } \\
\text { Seseorang yang memiliki sifat } \\
\text { kikir merasa dirinya kesusahan } \\
\text { dalam berinfak, meski dirinya } \\
\text { masih mampu. } \\
\text { Kikir berkaitan dengan tidak } \\
\text { adanya aktivitas tangan untuk } \\
\text { memberi dan berbagi kepada } \\
\text { sesama. }\end{array}$ \\
\hline
\end{tabular}

Makna metaforis: sifat seseorang yang tidak mau memberi sebagian rezekinya.

Tabel 2. Korespondensi Ranah Sumber dan Ranah Sasaran /yadāhu mabsūțatāni/

\begin{tabular}{|c|c|c|}
\hline Data Metafora & Ranah Sumber & Ranah Sasaran \\
\hline يَدَاهُ مَبْسُوْطنَتانِ & يَدَاهُ مَبْسُوْ طَتَانِ & رَخْمَنْ \\
\hline Iyadāhu $\quad$ mabsūțatānil & lyadāhu & |rahmān| \\
\hline kedua tangan-Nya terbuka keduanya & kedua tangan-Nya & Maha Pengasih \\
\hline \multirow[t]{2}{*}{$\begin{array}{l}\text { 'kedua tangan-Nya terbuka' (QS, } \\
5: 64) \text {. }\end{array}$} & $\begin{array}{l}\text { mabsūțatānil } \\
\text { keduanya terbuka }\end{array}$ & \\
\hline & $\begin{array}{l}\text { Pemetaan: } \\
\text { Secara kasat mata, konsep } \\
\text { tangan dapat diketahui } \\
\text { bentuk dan fungsinya. } \\
\text { Bagian tubuh yang biasa } \\
\text { digunakan sebagai alat } \\
\text { untuk memberikan suatu } \\
\text { barang maupun benda. } \\
\text { Terbuka merupakan lawan } \\
\text { dari keadaan suatu benda } \\
\text { atau entitas yang tidak } \\
\text { tertutup, tanpa penghalang. }\end{array}$ & $\begin{array}{l}\text { Pemetaan: } \\
\text { Allah swt. memiliki sifat } \\
\text { Maha Pengasih bagi } \\
\text { setiap makhluk ciptaan- } \\
\text { Nya. } \\
\text { Berdasarkan pengalaman, } \\
\text { tindakan ini umumnya } \\
\text { dilakukan oleh anggota } \\
\text { tubuh tangan. } \\
\text { Allah menganalogikan } \\
\text { sifat pengasih dengan } \\
\text { keadaan tangan yang } \\
\text { sedang terbuka. }\end{array}$ \\
\hline
\end{tabular}




Keadaan tangan yang
sedang membuka (tidak
mengepal/terbelenggu)
membuat pemiliknya dapat
melakukan pergerakan.
Memberi dan berbagi
umumnya dapat dilakukan
dengan membuka tangan
agar barang pemberian
dapat berpindah dari satu
tangan ke tangan lainnya.

Sifat ini dimiliki oleh Allah swt. karena tanpa kasihNya manusia tidak akan mampu hidup di dunia ini. Segala bentuk pemberian berupa kesehatan, rezeki, kemudahan, dan lain-lain adalah pemberian yang tak dapat diberikan oleh manusia.

Makna metaforis: sifat pengasih yang dimiliki oleh Allah Swt. kepada seluruh makhluk-Nya.

Pada tabel 1, metafora /yaqbiḍūna Paydiyahum/ 'mereka menggenggamkan tangan-tangannya' sebagai ranah sumber, dan /baxīlun/ 'kikir' sebagai ranah sasaran. Konsep sifat merupakan sesuatu yang abstrak. Pada saat keadaan menggenggam, kognisi pengalaman akan tertuju pada keadaan tangan yang terlihat mengepal, tertutup, dan tidak ada aktivitas lain yang dapat dilakukan. Keadaan demikian tidak memungkinkan adanya sesuatu yang dapat diberikan. Sama halnya dengan sifat |baxīlun/ 'kikir', orang yang kikir tidak mau memberikan sebagian rezekinya untuk membantu orang lain, baik dalam bentuk infak, sedekah, jariyah, dan zakat yang umumnya dilakukan dengan tangan.

Pada tabel 2, metafora /yadāhu mabsūțatāni/ 'kedua tangan-Nya terbuka' sebagai ranah sumber, dan Irahmān/ 'Maha Pengasih' sebagai ranah sasaran. Nomina يَ /yadun/ 'tangan' pada data ini dilekati oleh pronomina persona terikat maskulin tunggal yakni /hu/ pada kata /yadāhu/ 'tangan-Nya'. Pronomina persona ini merujuk kembali pada pemilik tangan yang dalam konteks kalimat ini adalah Allah Swt., Yang Maha Pemberi segalanya.

\section{Ranah Sasaran Pemalsuan}

Pemalsuan dimaknai sebagai suatu perbuatan memalsukan sesuatu yang sifatnya legal. Pada dasarnya, segala bentuk tindakan yang dilakukan tergantung pada niat. Otak lah yang merancang sedemikian rupa agar niat tindakan dapat dilakukan secara sistematis, dan tangan sebagai alat penggeraknya dapat dijalankan dengan baik. Apabila tindakan pemalsuan dikaitkan dengan tangan, tentu anggota tubuh ini memiliki peran penting. Berikut ini data metaforanya.

\begin{tabular}{lll} 
3. & & \\
\hline Iyaktubūna & '/-kitāba & bi-Paydīhim/ \\
mereka menulis & Kitab & dengan tangan-tangan mereka \\
'Menulis kitab dengan tangan mereka'. (OS, 2:79)
\end{tabular}

Berikut ini korespondensi kedua ranah serta makna metaforisnya.

Tabel 3. Korespondensi Ranah Sumber dan Ranah Sasaran /yaktubūna I-kitāba bi Paydīhim/

\begin{tabular}{|c|c|c|}
\hline Data Metafora & Ranah Sumber & Ranah Sasaran \\
\hline 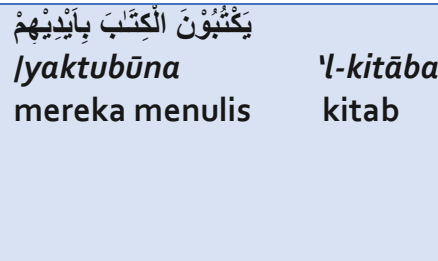 & 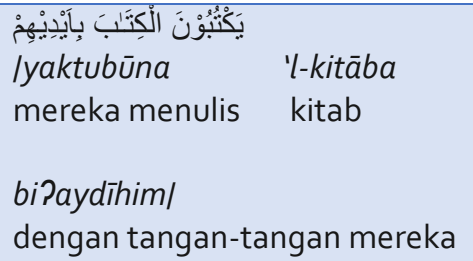 & $\begin{array}{l}\operatorname{sij}^{\prime} \\
\text { |tazyifun/ } \\
\text { pemalsuan }\end{array}$ \\
\hline $\begin{array}{l}\text { biPaydīhim/ } \\
\text { dengan tangan-tangan } \\
\text { mereka } \\
\text { 'mereka menulis kitab } \\
\text { dengan tangan mereka } \\
\text { sendiri' (QS, 2:79). }\end{array}$ & $\begin{array}{l}\text { Pemetaan: } \\
\text { Menulis secara kasat mata } \\
\text { umumnya dapat dilakukan oleh } \\
\text { anggota tubuh tangan. } \\
\text { Pada saat menulis, otak } \\
\text { mengeluarkan ide dan }\end{array}$ & $\begin{array}{l}\text { Pemetaan: } \\
\text { Tindakan pemalsuan dapat } \\
\text { dilakukan oleh anggota } \\
\text { tubuh yakni tangan. } \\
\text { Pemalsuan adalah bentuk } \\
\text { dari ide dan gagasan licik }\end{array}$ \\
\hline
\end{tabular}


pemikirannya yang abstrak ke

dalam bentuk tulisan.

Kitab suci berisi hukum Allah

Swt. yang tidak boleh diubah

oleh manusia.

Merekayasa isi kitab suci akan mendapat balasan hukuman berupa laknat dari Allah Swt. seseorang, salah satunya dalam bentuk tulisan. Umumnya tindakan ini dikenai pada sesuatu yang mendapat legalitas hukum.

Tindakan pemalsuan dapat dikenai hukuman karena telah melanggar ketentuan hukum yang ada.

Makna metaforis: proses memalsukan kitab (Taurat).

Data ini dapat diidentifikasi melalui koteks kata / Pal-kitāba/ 'kitab'. Umumnya, kognisi pengalaman kita mampu memahami bahwa menulis itu merupakan tindakan yang dilakukan oleh tangan. Akan tetapi, kalimat pada data ini memiliki konotasi negatif ketika yang ditulis oleh tangan ialah "kitab" yang isinya firman Tuhan. Kitab yang dimaksud dalam data ini yaitu Taurat.

\section{Ranah Sasaran Pertanggungjawaban}

Pertanggungjawaban dimaknai sebagai kewajiban menanggung segala sesuatu akibat perbuatan yang telah dilakukan. Berikut ini data metaforanya.

\begin{tabular}{|c|c|c|c|c|}
\hline \multirow[t]{6}{*}{ 4: } & \multicolumn{4}{|c|}{ 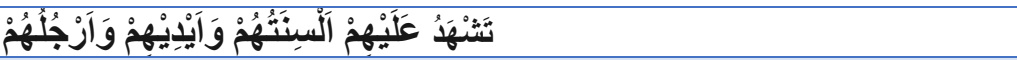 } \\
\hline & Itašhadu & Salayhim & Palsinatahum & $w a$ \\
\hline & bersaksi & atas mereka & lidah-lidah mereka & dan \\
\hline & \multicolumn{4}{|l|}{ Paydīhim/ } \\
\hline & \multicolumn{4}{|c|}{ tangan-tangan mereka } \\
\hline & \multicolumn{4}{|c|}{ 'lidah, tangan, dan kaki mereka menjadi saksi'. (OS, 24:24) } \\
\hline \multirow[t]{4}{*}{5 . } & \multicolumn{4}{|l|}{ 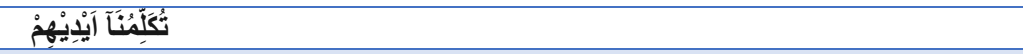 } \\
\hline & Itukallimunā & \multicolumn{3}{|c|}{ Paydīhim/ } \\
\hline & berbicara & \multicolumn{3}{|c|}{ tangan-tangan mereka } \\
\hline & \multicolumn{4}{|c|}{ 'tangan mereka akan berkata kepada Kami.' (OS, 36:65) } \\
\hline
\end{tabular}

Berikut ini korespondensi kedua ranah serta makna metaforisnya.

Tabel 4. Korespondensi Ranah Sumber dan Ranah Sasaran /tašhadu Salayhim Paydīhim/

\begin{tabular}{|c|c|c|}
\hline Data Metafora & Ranah Sumber & Ranah Sasaran \\
\hline 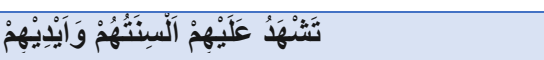 & 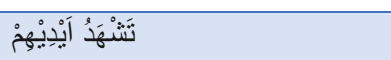 & مُسَاعَلَةُ \\
\hline $\begin{array}{l}\text { lyawma tašhadu Calayhim } \\
\text { hari } \\
\text { bersaksi atas mereka }\end{array}$ & $\begin{array}{l}\text { /tašhadu Paydīhim/ } \\
\text { tangan-tangan mereka } \\
\text { bersaksi }\end{array}$ & $\begin{array}{l}\text { Imusā̧alatun/ } \\
\text { pertanggungjawaban }\end{array}$ \\
\hline $\begin{array}{l}\text { Pal-sinatuhum wa Paydīhim/ } \\
\text { lidah-lidah mereka dan tangan- } \\
\text { tangan mereka }\end{array}$ & $\begin{array}{l}\text { Pemetaan: } \\
\text { Suatu tindakan yang } \\
\text { mana tangan akan }\end{array}$ & $\begin{array}{l}\text { Pemetaan: } \\
\text { Menyatakan hal-hal yang } \\
\text { terjadi atas apa yang telah } \\
\text { dilihat dan diperbuat. }\end{array}$ \\
\hline $\begin{array}{l}\text { '...lidah, tangan, dan kaki mereka } \\
\text { menjadi saksi atas mereka ...' } \\
(\mathrm{OS}, \mathbf{2 4 : 2 4 )} .\end{array}$ & $\begin{array}{l}\text { bersaksi di akhirat atas } \\
\text { apa yang telah dilakukan } \\
\text { semasa hidup. } \\
\text { Memberikan kesaksian di } \\
\text { hadapan Sang Pencipta. }\end{array}$ & $\begin{array}{l}\text { Memberikan kesaksian di } \\
\text { hadapan hakim atau pihak } \\
\text { yang berwenang. }\end{array}$ \\
\hline
\end{tabular}


Tabel 5. Korespondensi Ranah Sumber dan Ranah Sasaran /tukallimunā Paydīhim/

\begin{tabular}{|c|c|c|}
\hline Data Metafora & Ranah Sumber & Ranah Sasaran \\
\hline 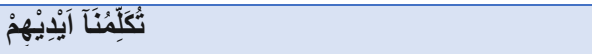 & 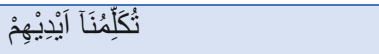 & مُسنَاعَلَة \\
\hline $\begin{array}{lc}\text { Itukallimunā } & \text { Paydīhim/ } \\
\text { Berbicara } & \text { tangan-tangan mereka }\end{array}$ & $\begin{array}{l}\text { Itukallimunā } \\
\text { berbicara }\end{array}$ & $\begin{array}{l}\text { ImusāYalatun/ } \\
\text { pertanggungjawaban }\end{array}$ \\
\hline \multirow[t]{2}{*}{$\begin{array}{l}\text { '...tangan-tangan mereka berbicara...' } \\
(\mathrm{QS}, 36: 65) .\end{array}$} & $\begin{array}{l}\text { Paydīhim/ } \\
\text { tangan-tangan mereka }\end{array}$ & \\
\hline & $\begin{array}{l}\text { Pemetaan: } \\
\text { Suatu tindakan yang } \\
\text { mana tangan akan } \\
\text { berbicara di akhirat atas } \\
\text { apa yang telah dilakukan } \\
\text { semasa hidup. } \\
\text { Memberikan pernyataan } \\
\text { di hadapan Sang } \\
\text { Pencipta. }\end{array}$ & $\begin{array}{l}\text { Pemetaan: } \\
\text { Menyatakan hal-hal } \\
\text { yang terjadi atas apa } \\
\text { yang telah dilihat dan } \\
\text { diperbuat. } \\
\text { Memberikan pernyataan } \\
\text { di hadapan hakim atau } \\
\text { pihak yang berwenang. }\end{array}$ \\
\hline
\end{tabular}

Makna metaforis: memberikan pernyataan pada saat persidangan hari kiamat.

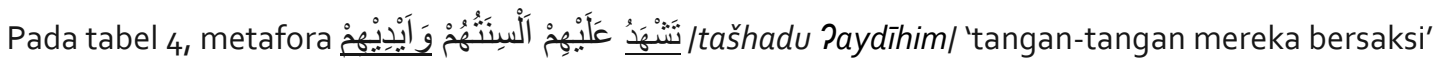
sebagai ranah sumber, dan /musā̧alatun/ 'pertanggungjawaban' sebagai ranah sasaran. Ranah sumber pada data ini ialah verba aktif /tašhadu/ 'bersaksi'. Bentuk ini termasuk kata kerja yang bermakna sedang atau akan terjadi. Hal tersebut berkaitan dengan hari kiamat yang akan terjadi seperti yang telah disebutkan di awal ayat dengan redaksi /yawma/ dan / Palyawma/ yang artinya 'pada hari tersebut'.

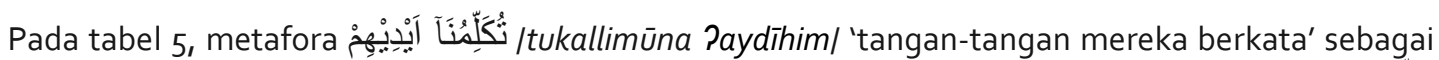
ranah sumber, dan /musā̧alatun/ 'pertanggungjawaban' sebagai ranah sasarannya. Verba /tukallimūna/ 'berkata' menjelaskan bahwa tangan akan dapat berbicara pada hari kiamat. Tindakan tersebut merujuk pada konsep pertanggungjawaban di akhirat kelak. Manusia tidak dapat mengetahui seperti apa persidangan di akhirat kelak, karena hal tersebut merupakan keadaan yang sifatnya abstrak (gayb) sehingga tidak dapat dijelaskan gambarannya berdasarkan pengalaman.

\section{Ranah Sasaran Kekuasaan}

Kekuasaan dalam pembahasan ini dimaknai sebagai kemampuan dalam menguasai suatu hal berdasarkan wewenang yang dimiliki. Tangan sebagai anggota tubuh memiliki peranan yang penting, salah satunya sebagai alat untuk berkuasa dan menjadi simbol memerintah. Berikut ini data metaforanya.

\begin{tabular}{|c|c|c|c|}
\hline \multirow[t]{4}{*}{6.} & \multicolumn{3}{|l|}{ بِيَدِهِ عُقَدَة النَّكَاح } \\
\hline & Ibiyadihī & Suqdatu & 'n-nikāhil \\
\hline & di tangannya & ikatan & pernikahan \\
\hline & 'Akad nikah a & $a^{\prime} .(O S$, & \\
\hline
\end{tabular}

\begin{tabular}{|c|c|c|}
\hline \multirow[t]{4}{*}{7.} & \multicolumn{2}{|l|}{ بِيَدِكَ الْخَيْرُ } \\
\hline & Ibiyadika & 'l-xayrul \\
\hline & di tangan Engkau & kebaikan \\
\hline & 'Di tangan Engkau & ajikan'. (OS, 3:26) \\
\hline
\end{tabular}

\begin{tabular}{|c|c|c|c|}
\hline \multirow{3}{*}{8.} & \\
\hline & & \multirow{2}{*}{$\begin{array}{l}\text { biyadi } \\
\text { di tangan }\end{array}$} & \multirow{2}{*}{$\begin{array}{l}\text { 'l-Lāhi/ } \\
\text { Allah }\end{array}$} \\
\hline & 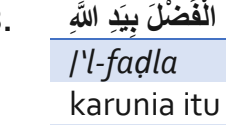 & & \\
\hline
\end{tabular}


Berikut ini korespondensi kedua ranah serta makna metaforisnya.

Tabel 6. Korespondensi Ranah Sumber dan Ranah Sasaran /biyadihï Suqdatu 'n-nikāhi/

\begin{tabular}{|c|c|c|}
\hline Data Metafora & Ranah Sumber & Ranah Sasaran \\
\hline 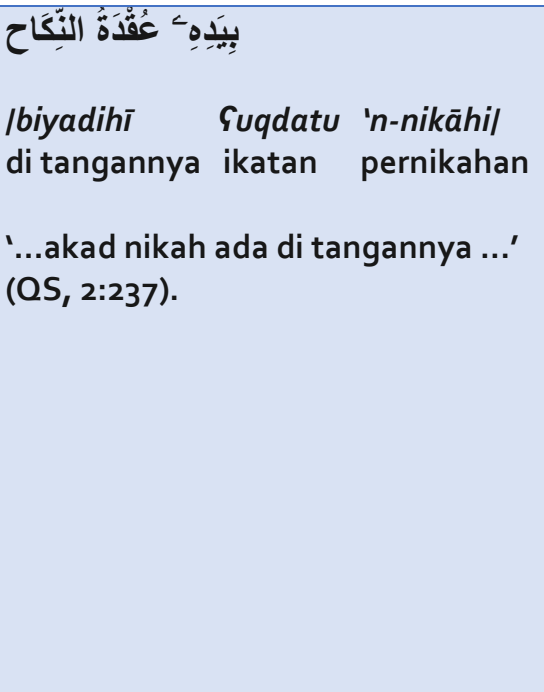 & 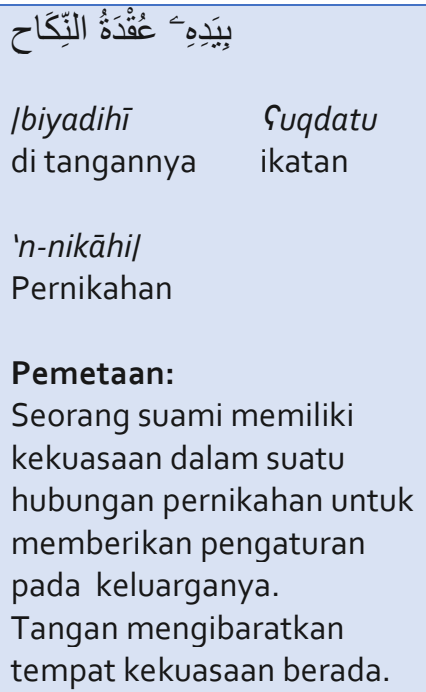 & $\begin{array}{l}\text { Pemetaan: } \\
\text { Kekuasaan identik dengan } \\
\text { kemampuan seseorang } \\
\text { dalam hal melakukan } \\
\text { pengaturan. } \\
\text { Tangan merupakan } \\
\text { anggota tubuh untuk } \\
\text { melakukan segala hal } \\
\text { berdasarkan kemampuan. }\end{array}$ \\
\hline
\end{tabular}

Tabel 7. Korespondensi Ranah Sumber dan Ranah Sasaran /biyadika I-xayru/

\begin{tabular}{|c|c|c|}
\hline Data Metafora & Ranah Sumber & Ranah Sasaran \\
\hline بِيَِِكَ الْخَيْرِ & بِيَِكِكَ الْخَيْرُ & قُوَّةَُّ \\
\hline $\begin{array}{ll}\text { lbiyadika } & \text { 'l-xayru/ } \\
\text { di tangan-Mu } & \text { kebajikan }\end{array}$ & $\begin{array}{ll}\text { lbiyadika } & \text { 'l-xayru/ } \\
\text { di tangan-Mu } & \text { kebajikan }\end{array}$ & $\begin{array}{l}\text { |quwwah/ } \\
\text { kekuasaan }\end{array}$ \\
\hline $\begin{array}{l}\text { '...di tangan Engkaulah segala } \\
\text { kebajikan...' (QS, 3:26). }\end{array}$ & $\begin{array}{l}\text { Pemetaan: } \\
\text { Tangan Allah (kiasan) } \\
\text { diibaratkan menggenggam } \\
\text { kebajikan. } \\
\text { Dalam konsep kebajikan } \\
\text { memiliki sesuatu yang } \\
\text { abstrak untuk dibagikan } \\
\text { kepada makhluknya. }\end{array}$ & $\begin{array}{l}\text { Pemetaan: } \\
\text { Kekuasaan identik dengan } \\
\text { kemampuan diri dalam } \\
\text { berbagai hal. } \\
\text { Siapa saja yang berkuasa } \\
\text { memiliki kewenangan dalam } \\
\text { mengatur segala bentuk } \\
\text { pemberian atas dasar } \\
\text { kekuasaan yang diemban. }\end{array}$ \\
\hline
\end{tabular}

Tabel 8. Korespondensi Ranah Sumber dan Ranah Sasaran /'I-fadla biyadi 'I-Lāhi/

\begin{tabular}{|c|c|c|}
\hline DM & RSU & Rsa \\
\hline الْفْضْل بِيَدِ اللَّهِ & الْفَضْلَ بِيَدِ اللَّهِ & ق فُوَّةٌُ \\
\hline I'l-fadla biyadi 'l-Lāhil & I'l-fadla biyadi 'l-Lāhil & |quwwah| \\
\hline karunia ditangan Allah & karunia ditangan Allah & kekuasaan \\
\hline '...karunia itu di tangan Allah ...' & Pemetaan: & Pemetaan: \\
\hline$(Q S, 3: 73)$ & $\begin{array}{l}\text { Pengibaratan tangan yang } \\
\text { sedang menggenggam } \\
\text { karunia. }\end{array}$ & $\begin{array}{l}\text { Kekuasaan identik dengan } \\
\text { kemampuan diri dalam } \\
\text { memiliki segala sesuatu. }\end{array}$ \\
\hline
\end{tabular}


Dalam konsep karunia memiliki sesuatu yang abstrak untuk dibagikan kepada makhluknya.
Siapa saja yang berkuasa memiliki kewenangan dalam mengatur segala bentuk pemberian atas dasar kekuasaan yang diemban.

Makna metaforis: menunjukkan kekuasaan Allah dalam memberikan karunia kepada makhlukNya.

Pada data 6, عُقْدَةُ النّبكَاح karena tidak dapat dipegang oleh tangan. Frasa tersebut menjadi penjelas nomina /yadun/. Data 7, الْخَيْرْ /'l-xayru/ 'kebajikan', merupakan sesuatu yang abstrak yang diumpamakan berada pada tangan. Data 8, الْفَضْلْ /'l-fadla/ 'karunia', merupakan sesuatu yang abstrak karena tidak dapat dipegang oleh tangan. Nomina-nomina tersebut menjadi penjelas kata /yadun/.

\section{Ranah Sasaran Menahan Emosi}

Menahan keinginan mencelakakan dimaknai sebagai emosi diri untuk tidak melakukan tindakan yang menyebabkan orang lain celaka. Hal tersebut tentu berkaitan dengan keadaan psikologis karena dipengaruhi oleh perilaku seseorang terhadap orang lain. Berikut ini data metaforanya.

\begin{tabular}{|c|c|c|}
\hline \multirow[t]{4}{*}{9.} & كُفْوَا أَِْدِيَكُمْ & \\
\hline & Ikuffū & Paydiyakum/ \\
\hline & tahanlah & tangan-tangan kalian \\
\hline & 'Tahanlah & $n g)^{\prime} .(\mathrm{QS}, 4: 77)$ \\
\hline
\end{tabular}

Berikut ini korespondensi kedua ranah serta makna metaforisnya.

Tabel 9. Korespondensi Ranah Sumber dan Ranah Sasaran /kaffa/ + /yadun/

\begin{tabular}{|c|c|c|}
\hline Data Metafora & Ranah Sumber & Ranah Sasaran \\
\hline كَفََّ يَاُ & كَفَّ بَدُ & أُوْقَفْ الْحَرْبَ \\
\hline \multirow[t]{2}{*}{$\begin{array}{l}|k a f f a|+\text { |yadun| } \\
\text { menahan tangan }\end{array}$} & $\begin{array}{l}\mid \text { kaffal + lyadun| } \\
\text { menahan tangan }\end{array}$ & $\begin{array}{l}\text { lPawqāfu } \\
\text { menghentikan }\end{array}$ \\
\hline & $\begin{array}{l}\text { Pemetaan: } \\
\text { Kemampuan untuk dapat } \\
\text { menahan laju pergerakan } \\
\text { tangan yang sedang } \\
\text { bergerak. } \\
\text { Pada saat tangan tertahan, } \\
\text { tidak ada gerakan tangan } \\
\text { yang dilakukan. }\end{array}$ & $\begin{array}{l}\text { Pemetaan: } \\
\text { Kemampuan diri untuk } \\
\text { dapat menghentikan upaya } \\
\text { mencelakakan orang lain } \\
\text { yang dilakukan oleh tangan. } \\
\text { Pada saat pertikaian } \\
\text { terhenti, tidak terjadi } \\
\text { keributan lagi. }\end{array}$ \\
\hline
\end{tabular}

Ranah sumber dalam metafora ini yaitu frasa / kaffa/ + /yadun/, dan ranah sasarannya yaitu /waqfu '/qitāll 'menghentikan pertikaian'. Secara kontekstual, data ini merujuk pada ayat-ayat yang menjelaskan upaya mencelakakan kaum muslimin. Namun demikian, Allah membantu kaum muslimin dengan cara menghentikan rasa keinginan untuk melakukan tindakan mencelakai itu.

\section{Ranah Sasaran Meluapkan Emosi (Mencelakai)}

Mencelakai dipahami sebagai rasa keinginan yang ada dalam diri untuk berbuat celaka terhadap lawan yang ada di hadapannya. Adapun makna mencelakai ini mengacu pada data metaforis yang merujuk pada keinginan melakukan penyerangan. Data berikut menunjukkan ungkapan metaforis dengan menggunakan unsur anggota tubuh يَد /yadun/ 'tangan' dalam Alquran yang merujuk makna penyerangan. 
Ranah Sasaran dalam Metafora Kata /Yadun/'Tangan' pada Alquran

\begin{tabular}{|c|c|c|c|}
\hline \multirow{4}{*}{10.} & \multicolumn{3}{|l|}{ 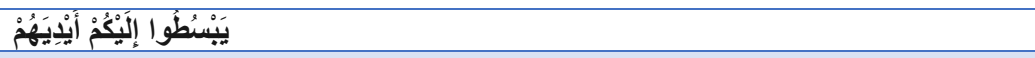 } \\
\hline & lyabsuțū & Pilaykum & Paydiyahum/ \\
\hline & Memanjangkan & kepada mu & tangan-tangan mereka \\
\hline & 'menyerang'. ( $\mathrm{Q}$ & & \\
\hline
\end{tabular}

Berikut ini korespondensi kedua ranah serta makna metaforisnya.

Tabel 10. Korespondensi Ranah Sumber dan Ranah Sasaran /yabsuțū Pilaykum Paydiyahum/

\begin{tabular}{|c|c|c|}
\hline Data Metafora & Ranah Sumber & Ranah Sasaran \\
\hline 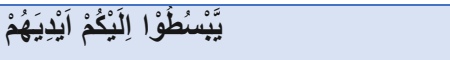 & 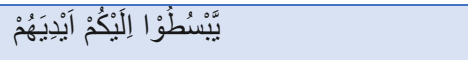 & هُجُوْم \\
\hline $\begin{array}{ll}\text { lyabsuțū } & \text { Pilaykum } \\
\text { memanjangkan } & \text { kepadamu }\end{array}$ & $\begin{array}{ll}\text { lyabsuțū } & \text { Pilaykum } \\
\text { memanjangkan } & \text { kepadamu }\end{array}$ & $\begin{array}{l}\text { /hujūm/ } \\
\text { penyerangan }\end{array}$ \\
\hline $\begin{array}{l}\text { Paydiyahum/ } \\
\text { tangan-tangannya }\end{array}$ & $\begin{array}{l}\text { Paydiyahum/ } \\
\text { tangan-tangannya }\end{array}$ & \\
\hline '...menyerang...' (QS, 111:1). & $\begin{array}{l}\text { Pemetaan: } \\
\text { Keadaan tangan yang } \\
\text { memanjang untuk mengenai } \\
\text { orang yang ada di hadapannya. }\end{array}$ & $\begin{array}{l}\text { Pemetaan: } \\
\text { Tindakan yang dilakukan } \\
\text { dengan menggerakkan } \\
\text { tangan untuk mengenai } \\
\text { lawan di hadapannya. }\end{array}$ \\
\hline
\end{tabular}

Makna metaforis: upaya penyerangan yang dilakukan kepada lawan.

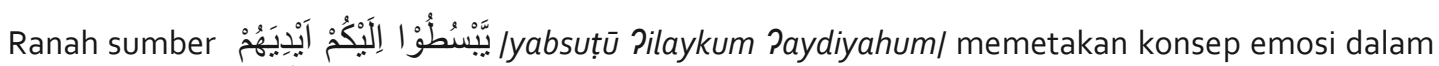
ranah sasaran هُجُوُْْم:hujūmun/ 'penyerangan'. Kedua ranah ini menjelaskan keadaan tangan yang melakukan pergerakan untuk menaklukan atau menghancurkan lawan. Apabila dilihat dari konteks, menyerang merupakan tindakan yang terjadi pada saat peperangan dengan menggunakan pedang sebagai alat utamanya. Pengalaman kita dapat memahami bahwa pada saat melakukan penyerangan, keadaan tangan akan dibentangkan selebar-lebarnya sambil memegangi pedang untuk mengenai lawan. Penyerangan juga dapat dilakukan dengan melempari batu kepada pihak lawan dengan membentangkan tangan dan mengayunkannya agar batu terlepas dari genggaman menuju sasaran.

\section{Ranah Sasaran Kerugian}

Kerugian dimaknai sebagai hasil dari tindakan yang dilakukan yang dianggap menimbulkan rugi. Pada hakikatnya, di dalam agama mana pun manusia diajarkan untuk melakukan tindakan baik dan terpuji. Begitu juga dalam Alquran. Banyak penjelasan ayat yang berisi larangan-larangan untuk melakukan tindakan ini melalui beberapa redaksi, salah satunya menggunakan bentuk metafora. Berikut ini data metaforanya.

\begin{tabular}{|c|c|c|c|c|}
\hline \multirow[t]{4}{*}{11.} & \multicolumn{4}{|c|}{ 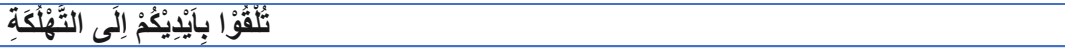 } \\
\hline & Itulqū & biPaydīkum & Pilā & 't-tahlukatil \\
\hline & kamu jatuhkan & dengan tangan-tangannya & kepada & kebinasaan \\
\hline & \multicolumn{4}{|c|}{ 'Kamu jatuhkan ke dalam kebinasaan dengan tangan sendiri'. (QS, 2:195) } \\
\hline \multirow[t]{4}{*}{12.} & تَبَبَتُ يَدَآ & & & \\
\hline & Itabbat & yadāl & & \\
\hline & binasalah & kedua tan & & \\
\hline & 'Binasalah kedu & ngan'. (QS, 111:1) & & \\
\hline
\end{tabular}

Berikut ini korespondensi kedua ranah serta makna metaforisnya. 
Tabel 11. Korespondensi Ranah Sumber dan Ranah Sasaran /tulqū bißaydīkum/

\begin{tabular}{|c|c|c|}
\hline Data Metafora & Ranah Sumber & Ranah Sasaran \\
\hline تُلْقُوْا بِآَيْدِيْكُمْ & تُلْقُوْا بِآَيْيْيْكُمْ & خَسَارَةٌ \\
\hline $\begin{array}{l}\text { biPaydīkum/ } \\
\text { tangan- }\end{array}$ & $\begin{array}{ll}\text { /tulqū } & \text { bißaydīkum/ } \\
\text { jatuhkan } & \text { tangan-tanganmu }\end{array}$ & $\begin{array}{l}\text { |xasārah| } \\
\text { kerugian }\end{array}$ \\
\hline $\begin{array}{l}\text { '...jatuhkan dengan tangan...' } \\
\text { (QS, 2:195). }\end{array}$ & $\begin{array}{l}\text { Korespondensi: } \\
\text { Keadaan tangan yang } \\
\text { terhempas ke bawah, yang } \\
\text { mana posisi bawah ini merujuk } \\
\text { posisi terendah dari posisi } \\
\text { semula. } \\
\text { Keadaan tersebut membuat } \\
\text { tangan terasa sakit. }\end{array}$ & $\begin{array}{l}\text { Korespondensi: } \\
\text { Keadaan terpuruk akibat } \\
\text { tindakan yang telah } \\
\text { dilakukan. } \\
\text { Kerugian dapat membuat } \\
\text { sengsara karena telah } \\
\text { melakukan tindakan yang } \\
\text { sia-sia. }\end{array}$ \\
\hline
\end{tabular}

Makna metaforis: kerugian akibat tidak berinfak untuk membantu jihad kaum muslim.

Tabel 12. Korespondensi Ranah Sumber dan Ranah Sasaran /tabbat yadā/

\begin{tabular}{|c|c|c|}
\hline Data Metafora & Ranah Sumber & Ranah Sasaran \\
\hline تَبَّبتْ بَدَآ & تَبَتَتْ بَدَاَ & خَسَارَةُّ \\
\hline $\begin{array}{cl}\text { Itabbat } & \text { yadāl } \\
\text { binasa } & \text { kedua tangan }\end{array}$ & $\begin{array}{cl}\text { Itabbat } & \text { yadāl } \\
\text { binasa } & \text { kedua tangan }\end{array}$ & $\begin{array}{l}\text { lxasārah/ } \\
\text { kerugian }\end{array}$ \\
\hline $\begin{array}{l}\text { 'Binasalah kedua tangan...' } \\
(\mathrm{QS}, 111: 1) .\end{array}$ & $\begin{array}{l}\text { Korespondensi: } \\
\text { Keadaan tangan yang hancur } \\
\text { dan tidak dapat kembali } \\
\text { seperti semula. } \\
\text { Keadaan tersebut dapat } \\
\text { membuat sengsara karena } \\
\text { tidak dapat berbuat sesuatu } \\
\text { yang lebih optimal. }\end{array}$ & $\begin{array}{l}\text { Korespondensi: } \\
\text { Keadaan terpuruk akibat } \\
\text { tindakan yang telah } \\
\text { dilakukan. } \\
\text { Kerugian dapat membuat } \\
\text { sengsara karena telah } \\
\text { melakukan tindakan yang } \\
\text { sia-sia. }\end{array}$ \\
\hline \multicolumn{3}{|c|}{$\begin{array}{l}\text { Makna metaforis: kerugian yang amat sangat disebabkan amal perbuatan dan usahanya } \\
\text { telah tersesat. }\end{array}$} \\
\hline
\end{tabular}

\section{KESIMPULAN}

Berdasarkan temuan dan hasil analisis menyatakan bahwa metafora dengan unsur kata /yadun/ 'tangan' dalam Alquran membandingkan ranah sasaran yang abstrak melalui ranah sumber yang dekat dengan pengalaman yang dikenai oleh tangan. Ranah sasaran yang terdapat dalam metafora berunsur kata /yadun/ 'tangan' dalam Alquran terdiri dari: (1) ranah sasaran sifat, (2) ranah sasaran pemalsuan, (3) ranah sasaran pertanggungjawaban, (4) ranah sasaran kekuasaan, (5) ranah sasaran menahan emosi, (6) ranah sasaran meluapkan emosi (mencelakai), dan (7) ranah sasaran kerugian. Selaras dengan hakikat kitab suci yang berisi ajaran dan ajakan kebaikan, metafora dengan unsur kata /yadun/ 'tangan' dalam Alquran secara tersirat merujuk pada larangan melakukan tindakan perusakan, maksiat, dan tercela.

\section{DAFTAR PUSTAKA}

Arimi, Sailal. 2015. Linguistik Kognitif. Yogyakarta: A.com Press.

Djajasudarma, T. Fatimah. 2010. Metode Linguistik. Bandung: PT Refika Aditama.

Evans, Vyvyan, dan Melanie Green. 2006. Cognitive Linguistics: An Introduction. Edinburgh: Edinburgh University Press Ltd. 
Golzadeh, Ferdows Agha dan Shirin Pourebrahim. 2013. Death Metaphor in Religious Texts: A Cognitive Semantics Approach. Vol. 20, No. 4. Tarbiat Modares University: The Internasional Journal of Humanities. Hal. 61-88.

Kövecses, Zoltán. 2010. Metaphor: A Practical Introduction. Edisi kedua. Oxford: Oxford University Press.

Kridalaksana, Harimurti. 2008. Kamus Linguistik. Edisi keempat. Jakarta: PT Gramedia Pustaka Utama

Kushartanti, Untung Yuwono, dkk. 2009. Pesona Bahasa: Langkah Awal Memahami Linguistik. Jakarta: PT. Gramedia Pustaka Utama.

Lakoff, George dan Mark Johnson. 2003. Metaphor We Live By. Chicago: The University of Chicago Press.

Lyra, Hera Meganova, dkk. 2016. Metafora Mati (Dead Metaphor) dalam Bahasa Sunda. Vol. 6 No. 2. Metahumaniora: Jurnal Bahasa, Sastra, dan Budaya. Hal. 189-199.

Moleong, Lexy J. 2011. Metodologi Penelitian Kualitatif. Edisi revisi. Bandung: PT. Remaja Rosdakarya.

Saeed, John I. 2016. Semantics. Edisi keempat. Oxford: Blackwell Publishers Ltd.

Sudaryanto. 2015. Metode dan Aneka Teknik Analisis Bahasa. Yogyakarta: Sanata Dharma University Press. 